\title{
Orchestrating coordination among humanitarian organizations
}

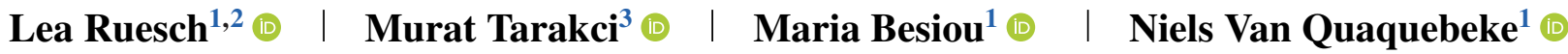

${ }^{1}$ Department of Operations \& Technology, Department of Leadership \& Management, Kuehne Logistics University (KLU), Hamburg, Germany

${ }^{2}$ Department of Psychological and Behavioural Science, London School of Economics and Political Science (LSE), London, UK

${ }^{3}$ Department of Technology and Operations Management, Rotterdam School of Management, Erasmus University, Rotterdam, Rotterdam, The Netherlands

\section{Correspondence}

Maria Besiou, Department of Operations \& Technology, Kuehne Logistics University, Großer Grasbrook 17, 20457 Hamburg, Germany.

Email: Maria.besiou@the-klu.org

Funding information

Studienstiftung Des Deutschen Volkes

Handling editor: Sushil Gupta

\begin{abstract}
Disasters mobilize hundreds of organizations, but coordination among them remains a challenge. This is why the United Nations has formed clusters to facilitate information and resource exchange among humanitarian organizations. Yet, coordination failures in prior disasters raise questions as to the effectiveness of the cluster approach in coordinating relief efforts. To better understand barriers to coordination, we developed a grounded theory and augmented the theory with an agent-based simulation. Our theory discerns a cluster lead's roles of facilitating coordination, but also investing in its own ground operations. We find that specifically serving such a dual role impairs swift trust and consequent coordination among cluster members. The additional simulation findings generalize the detrimental effect of the cluster lead's dual role versus a pure facilitator role and specify it against various boundary conditions.
\end{abstract}

\section{K E Y W OR D S}

agent-based simulations, coordination, humanitarian operations, interorganizational relationships, leadership, localization, resource disparity, swift trust

\section{1 | INTRODUCTION}

Following disasters, humanitarian organizations (HOs) from all over the world assemble to save as many lives as possible. Despite the best intentions of those involved, coordination problems among HOs often yield redundant efforts and resources (Altay \& Pal, 2014; Balcik et al., 2010; Eftekhar et al., 2017; Moshtari, 2016; Moshtari \& Gonçalves, 2011). These inefficiencies are regrettable since every bit of humanitarian aid counts in saving and improving lives. This is why the United Nations' (UN) final sustainable development goal calls for more effective partnerships (United Nations, 2016).

To improve coordination among HOs, the UN itself began installing coordination clusters in 2005 , each led by a cluster lead agency. Humanitarian operations research has long advocated clusters and their leads as "the most important factor" in coordinating HOs and their representatives (Tomasini \& Van Wassenhove, 2009, p. 86). However, despite the activation of clusters and their leads, coordination is still challenging in the field. Consider the 2010 Haiti earthquake (CBC,

Accepted by Sushil Gupta, after 1 revision.

This is an open access article under the terms of the Creative Commons Attribution-NonCommercial License, which permits use, distribution and reproduction in any medium, provided the original work is properly cited and is not used for commercial purposes.

(C) 2022 The Authors. Production and Operations Management published by Wiley Periodicals LLC on behalf of Production and Operations Management Society
2012): Here, clusters were activated to support coordination among more than 1000 HOs (ALNAP \& UNEG, 2011; Altay $\&$ Labonte, 2014). Despite all efforts to coordinate, the disasp. 1). To understand why coordination in the cluster might struggle despite the advised involvement of a cluster lead, our central research question investigates how the cluster lead's role impacts coordination among the cluster members.

Since disaster response is a complex and dynamic process, we follow the recent recommendation for multi-method approaches (Besiou \& Van Wassenhove, 2015; Chandrasekaran et al., 2018; Sting et al., 2019) to answer this question. Specifically, we combine a qualitative, grounded theory approach with agent-based simulation. First, our qualitative analysis unearthed that the cluster lead's dual role both as facilitator of cluster meetings and as an active $\mathrm{HO}$ in the disaster response prompts struggles over resources and harms trust among cluster members. Specifically, HOs question whether the cluster lead favors its own agenda over the other HOs, subsequently hesitating to share their local knowledge and resources and thus derailing the relief efforts. Second, we developed an agent-based simulation ter response was deemed a "failure" (Altay \& Labonte, 2014, 
model (ABS) to both augment the grounded theory and to delineate its boundary conditions. While the theory clarifies the negative effect of the cluster lead's dual role in relation to a pure facilitator, the qualitative study lacked the counterfactual where the lead was absent. The simulation model allows us to have direct comparisons of different scenarios and delineate boundary conditions. While the simulation results confirm prior research highlighting the benefits of cluster leadership (Altay \& Pal, 2014), we enhance these prior assertions by studying the different roles that a cluster lead plays. We find that, in most cases, pure facilitation satisfies needs and distributes logistical resources better than a dual role.

We contribute to research on humanitarian operations and interorganizational coordination in three ways: First, prior research stresses the need to study leadership and group dynamics in the humanitarian operations context, shaped by limited resources and high pressure to perform (e.g., Altay \& Pal, 2014; Arslan \& Tarakci, 2022; Gunasekaran et al., 2018; Jensen, 2012; Sankaranarayanan et al., 2018; Tomasini \& Van Wassenhove, 2009). Related research in humanitarian logistics has developed arguments in favor of an orchestrator serving as the integrator, decision-maker, infomediary, resource provider, and implementor (e.g., Abidi et al., 2015; Jensen, 2012). Although we find that any cluster leadership is better than none, it seems that enacting multiple roles can have detrimental effects on coordination. Our results generally advocate a pure facilitator role over a dual role. Interorganizational relationships face an ongoing battle between the spirit of collaboration and manipulating the collaborative agenda (Vangen \& Huxham, 2003a). As such, our finding about the pure facilitator also adds a specific leadership strategy to studies about the simultaneous interplay between cooperation and competition (Hoffmann et al., 2018; Stadtler \& Van Wassenhove, 2016). Likewise, it addresses the recent calls to investigate coopetition and its antecedents in resource-scarce environments (Hoffmann et al., 2018).

Second, research has shown the role of trust in interorganizational coordination (Altay \& Pal, 2014; Brinkhoff et al., 2015; Mortensen \& Neeley, 2012; Özer et al., 2018), and specifically the salience of swift trust. Swift trust is a presumptive form of trust, where participants in temporary organizations come to trust each other ex ante, and subsequent interactions verify or adjust their trust (Dubey et al., 2019; Lu et al., 2018; Meyerson et al., 1996; Schiffling et al., 2020). We show that a combination of resource disparities and the dual role can damage swift trust and ignite dysfunctional dynamics among HOs.

Third, our analysis on boundary conditions adds to prior research on coordination practices (Faraj \& Xiao, 2006; Frennesson et al., 2020; Minson et al., 2018) and the involvement of local HOs in disaster response (Berenguer \& Shen, 2019; Lewin et al., 2018; Salem et al., 2017, 2019). We show that the absence of local HOs and their first-hand information can encourage misaligned priorities that ultimately lead to fewer logistical needs being satisfied through disaster response.

The following section reviews the operations management and humanitarian logistics literature to frame our present research effort. In Section 3, we introduce our qualitative study and its findings. Section 4 then features the ABS model and its results. Finally, we more broadly interpret and discuss the present findings from the lens of humanitarian operations and behavioral research in Section 5 .

\section{2 | THEORETICAL BACKGROUND}

Successful disaster response requires coordination among HOs, defined here as "the relationships and interactions among different actors operating within the relief environment" (Balcik et al., 2010, p. 23). Indeed, when hundreds of aid agents engage in an affected region, researchers and practitioners emphasize the necessity of sharing resources and information among HOs to improve disaster response (Altay \& Labonte, 2014; Altay \& Pal, 2014; Ergun et al., 2014; Moshtari, 2016). The need for effective coordination is further underscored by the complexity of the humanitarian ecosystem consisting of various organizations-all having specific agendas. In this complex web, coordination becomes essential where only "by working together, actors can realize something that none of them can achieve unilaterally and which is also more important than their own profit maximization" (Stadtler \& Van Wassenhove, 2016, p. 658). However, simultaneous cooperation for disaster response and competition over scarce resources pose a barrier to successful coordination (Eftekhar et al., 2017; Hoffmann et al., 2018; Stadtler \& Van Wassenhove, 2016). To avert coordination failures, prior research has advocated a "cluster lead" to coordinate HOs within the cluster (Jensen, 2012). Tomasini and Van Wassenhove (2009, p. 77) advise that representatives "who are recognized as knowledgeable and reliable" assert leading roles and serve as credible partners. Altay and Pal (2014) echoed this sentiment, finding in a simulation study that the presence of a cluster lead improves information diffusion and response.

Prior research further outlines the multiple roles that cluster leads should play. Specifically, scholars coined the term fourth-party logistics (4PL) provider as "a supply chain integrator that assembles and manages the resources, capabilities, and technology of its own organization with those of complementary service providers to deliver a comprehensive supply chain solution" (Jensen, 2012, p. 153). These roles comprise being an integrator, decision-maker, infomediary, resource provider (Abidi et al., 2015; Jensen, 2012; Win, 2008), as well as implementor (Jensen, 2012). Jensen (2012, p. 157) concluded that cluster leads (e.g., World Food Programme [WFP]) should be considered as "a large organization carrying out many operational tasks, and with elements of 4PL tasks on top of this."

Yet, it is not clear how cluster leads enact these roles and how the cluster lead's roles aid or harm coordination. A deeper understanding of cluster lead's roles is important given the ongoing reports of coordination difficulties, despite the existence of a cluster and the urgent pressures felt amid disasters (e.g., Altay \& Labonte, 2014; Knox-Clarke \& 
Campbell, 2015; Lewin et al., 2018). Importantly, understanding the roles-and the respective behaviors and motives - that HOs enact requires a behavioral perspective. However, such a behavioral perspective remains unexamined for interorganizational coordination issues in the humanitarian operations literature, despite calls for behavioral insights that would provide a better understanding of operational challenges (Gunasekaran et al., 2018; Jahre \& Jensen, 2010; Moshtari \& Gonçalves, 2011).

Our central research question is, therefore, how the cluster lead's roles impact coordination among the cluster members. To inductively understand the roles that a cluster lead plays in coordinating disaster response, we first conduct a qualitative analysis of cluster meetings (Gehman et al., 2018; Gioia et al., 2013). While we first engage in a grounded theory development around the underlying dynamics, counterfactuals and boundary conditions remain hidden in the field. To unveil these hidden elements, we subsequently develop an ABS to augment the emerging theory.

\section{3 | STUDY 1: A QUALITATIVE, INDUCTIVE STUDY OF COORDINATION IN HUMANITARIAN OPERATIONS}

The main research question we investigate in Study 1 is how the cluster lead coordinates HOs. Using qualitative expert interviews and a grounded theory approach, we seek to gain fresh insight into the interactions between a cluster lead and members in LogCluster meetings, a central platform where organizations coordinate their efforts in the field. Our level of analysis is the cluster, which consists of the cluster lead and cluster member organizations. Following grounded-theory approaches (Gioia et al., 2013; Nag \& Gioia, 2012; Villena \& Gioia, 2018), we gathered primary information mainly from the individuals representing the lead or a cluster member organization. The emergent patterns were shared by individuals speaking on behalf of their organization and thus pertain to an organizational level (Gioia, 2021; Nag \& Gioia, 2012). Thus, the individual and organizational levels are convergent, which makes the cluster our unit of analysis, consisting of cluster lead and cluster member organizations.

\section{1 | Empirical context}

The UN founded the cluster system in 2005 to improve responses to disasters and to formalize the lead role for main sectors in humanitarian action, for example, health, food, and logistics. Our qualitative, inductive research focuses on the LogCluster, a leading cluster in the UN's cluster system. The LogCluster offers coordination and information management to support operational decision-making and to improve the predictability, timeliness, and efficiency of disaster response (LogCluster, 2019).

The cluster lead organizes meetings among HOs to facilitate coordination (Jahre \& Jensen, 2010; LogCluster,
2019; Tomasini \& Van Wassenhove, 2009). WFP leads the LogCluster due to its expertise in the field of humanitarian logistics, where it also acts as the "provider of last resort" for common logistics services "when critical gaps hamper the humanitarian response" (LogCluster, 2019). The cluster lead may vary per country. In Venezuela, for example, the Office for the Coordination of Humanitarian Affairs (OCHA) acts as the lead agency for LogCluster. Once a cluster is activated, voluntary field meetings are held regularly involving local and international HOs. These meetings are mostly organized and directed by staff from the cluster lead, backed up by other cluster members. To engage the urgent and sudden nature of disasters, cluster meetings often enlist many participants in a hurried fashion, especially at the onset of a disaster. The LogCluster in a disaster area stands down when logistics gaps and bottlenecks have been treated to reduce humanitarian needs and coordination gaps, or when the nation itself acquires sufficient capacity to coordinate and meet the needs (LogCluster, 2019).

In the rest of the paper, we refer to both the network of cluster members and the LogCluster as the cluster while calling the head agency the cluster lead. LogCluster representatives serve as the cluster staff. Next, we detail our inductive approach to safeguard replicability (Aguinis \& Solarino, 2019).

\section{2 | Data collection}

We collected data from primary and secondary sources. To capture as many primary sources as possible, the lead author contacted logistics managers and coordinators from various HOs. Consistent with traditional grounded-theory approaches, the sampling logic moved from purposive to theoretical sampling, with the objective of collecting data to further analyze the theoretical framework emerging from earlier data collections (Glaser \& Strauss, 1967). In this spirit, we sought organizational (financial spectrum, regional scope) and individual (nationality, gender, occupations, rank) variety to capture the diverse experiences of cluster meetings. We obtained contacts through international conferences and supply chain workshops where practitioners are the main audience. The final sample (see Table 1) includes various aid agents who, on average, had been working in humanitarian logistics for 10 years. During their careers, they often attended cluster meetings in response to natural and humanmade disasters in countries such as South Sudan, Central Africa Republic, Fiji, Indonesia, the Philippines, Myanmar, Bangladesh, Nepal, Yemen, Syria, and Haiti. This diverse sample functions as a vital lever to research the complex array of interorganizational relationships in cluster meetings.

We conducted 21 qualitative semistructured interviews over 7 months to gain insights regarding the cluster's experiences and concerns with regard to field coordination. We interviewed the representatives of the cluster lead and member organizations. Semistructured interviews constitute the heart of qualitative research, as they enable insights into 
TA B L E 1 Sample and data triangulation

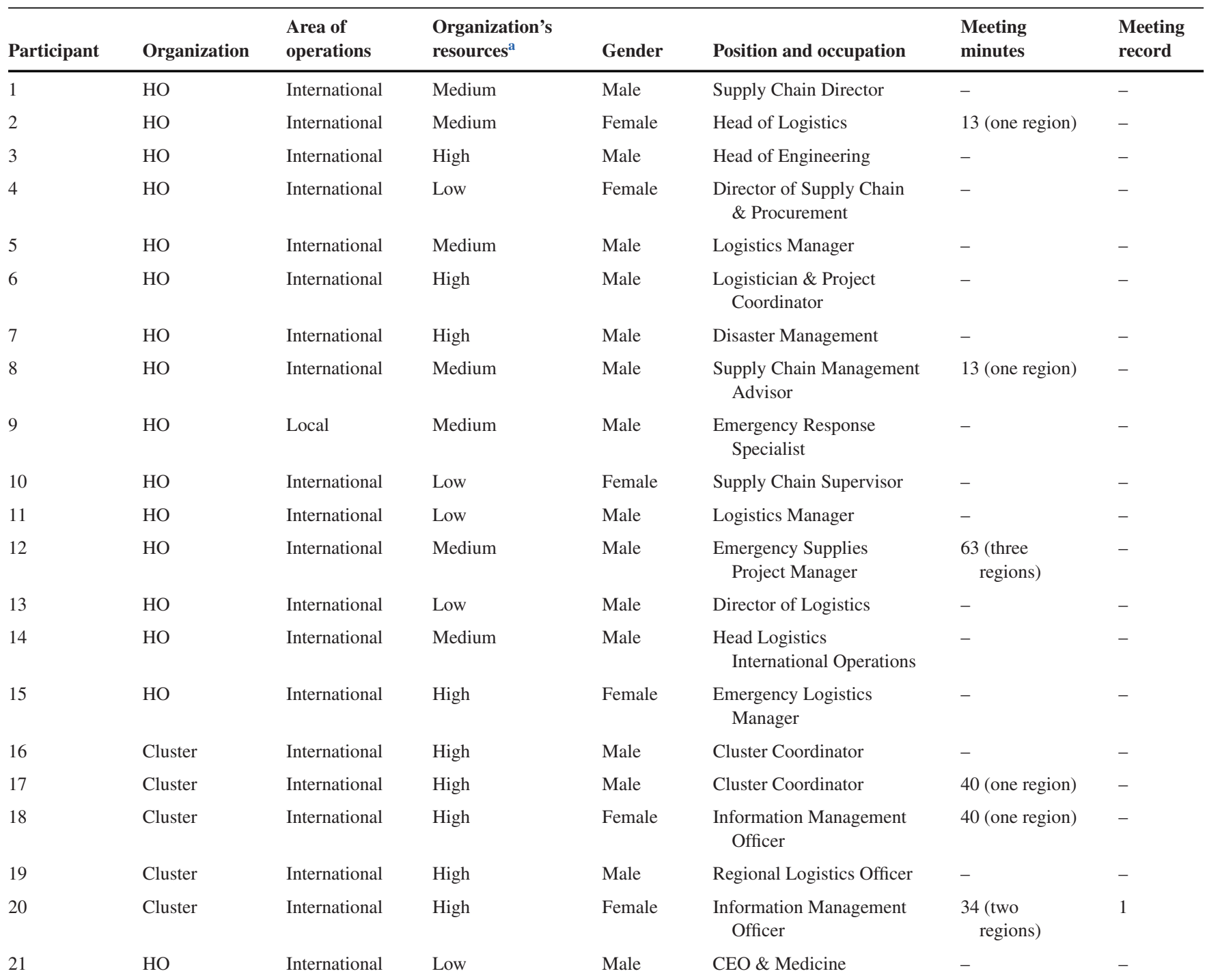

${ }^{\mathrm{a}}$ Total income of organization retrieved from annual reports with donations exceeding 1 billion $=$ high financial resources, more than 500 million $=$ medium financial resources, and less $=$ low financial resources.

retro- and real-time perspectives shared by people experiencing the phenomenon of theoretical interest (Gioia et al., 2013). In line with traditional grounded-theory methods, we conceived our study participants as knowledgeable agents able to explain their thoughts, intentions, and actions (Gioia et al., 2013).

As such, our initial interview protocol (see the Supporting Information Appendix) aligned with our research objective while avoiding leading questions and imposing theoretical views. Initial interviews thus involved more general questions about the cluster and member experiences in cluster meetings. Later interviews became progressively more structured as themes emerged in the data. Importantly, our questions referring to cluster members as organizations and their representatives gave participants the opportunity to relate their individual experiences to interorganizational coordination. Interviews averaged $60 \mathrm{~min}$, and we guaranteed anonymity and confidentiality. To maintain consistency, the lead author conducted all interviews. We noticed that after 15 interviews, additional informants did not lead to new discoveries concerning the central theme of the dual role and pure facilitation. However, later interviews helped to validate and deepen our understanding of central themes and their respective insights.

We complemented the interviews with secondary sources in form of 163 meeting minutes from the LogCluster website concerning disaster responses specifically cited by the interviewees. Minutes aided us in developing a better understanding of these challenges and conditions. Aside from the participant details, Table 1 states the number of minutes we used to triangulate experiences in specific disasters that the participants explicitly referred to. Some participants referred to the same regions, which is why there are overlaps and the total number of minutes in Table 1 exceeds 163. Further, we used 900 meeting minutes to score average participation levels in meetings. Here, we observed an average of 10 
meeting participants per disaster across 45 countries. Note that the dangerous nature of the disasters did not allow the authors to attend actual field meetings. Nevertheless, we obtained an actual audio recording from one cluster meeting that helped us develop a better understanding of meeting dynamics and atmosphere as well as confirm alignment with meeting minutes transcriptions.

\section{3 | Data analysis}

Using the Nvivo software, we conducted an open-coding analysis (Corbin \& Strauss, 2014) of the interview transcripts by selecting, categorizing, and labeling themes (Gioia et al., 2013). We coded each interview separately on the basis of terms or phrases used by the informants, as suggested by Miles and Huberman (1994), before starting to crossanalyze emergent patterns across different interviews. That is, we read each interview several times to identify similarities and idiosyncrasies among informants (Glaser \& Strauss, 1967). We then collated them into first-order themes that represent key constructs adhering closely to informant verbiage. Repeating this procedure, we got to the point when we did not ascertain any more distinct patterns among informants. Next, these themes were distilled into more organized, second-order themes. These researcher-induced themes are more abstract and theoretically distinctive. However, we tried to stay close to informant labels if those labels represented theoretical concepts. Following Lincoln and Guba (1985), we meticulously managed our data, including contact records, interview transcripts, and subanalyses. We further discussed our analyses and emerging data patterns not only among the author team, but also with unaffiliated researchers from similar and other research fields. We further compared the themes raised by interviewees with information from respective meeting minutes and records - a triangulation of primary and secondary data that offered rich insights. The themes, their relationships, and meanings were finally collected into aggregate, theoretical dimensions: coordination, resource disparity, resource struggles, roles, swift trust, and information accuracy. The data structure is shown in the Supporting Information, while it provides respective exemplary quotes from interviews and minutes. Finally, the aggregate dimensions enabled us to develop a grounded theory that links the various concepts emerging from the data. The next section describes the data structure in detail.

\section{4 | Findings: The constitutive elements of a grounded theory}

\subsection{1 | Coordination}

As captured in the first aggregate dimension, that is, coordination, the overarching objective of the LogCluster is to bring relevant actors together in cluster meetings and share information to optimize the disaster response. After a disas- ter occurs, it is necessary to accurately assess the needs for logistical resources, enumerate available resources, and provide orientation. This means enlisting as many members as possible in the cluster meetings.

In the beginning of crisis there is, of course, a big demand for information. Exchange is not the main thing, but the affected people and organizations ask for orientation. There is more information on the situation, which is released, and at the end are any prioritized questions where one gets feedback. That's it. There is no vivid exchange. After a certain time when the pressure for the organization increases to show results, then a higher demand for requests occurs. This means that one almost aggressively asks for resources. (Participant 8; Quote 1)

\subsection{2 | Resource disparity}

Because coordination requires the exchange of information regarding logistics resources, the interviews revealed the prevalence of resource disparities in governing those exchanges. First, local HOs are often smaller, but their onsite knowledge and network on the ground make them key players. Second, international HOs are larger, and usually have more financial resources than local HOs. Third, the cluster lead is large, well-endowed, and its staff plays the role of that cluster coordinator that acts as the "honest broker" for all stakeholders. Given their diversity in views and capabilities alongside the common objective to deliver aid as efficiently and effectively as possible, HOs need the cluster. As one interviewee stated:

Overall for NGOs, they have small resources and small money ... the cluster is the only help. (Participant 4; Quote 2)

Meeting minutes and records from field clusters reflect dependency on the cluster lead as the last resort, which ultimately makes the final decisions in terms of resource allocations:

The LogCluster, as a coordination mechanism, does not facilitate air cargo transport to locations that are accessible by road, except in cases of extreme emergencies. Many locations in Jonglei State are now available by road. Registrations for air transport will no longer be accepted for these locations until further notice, except in case of emergency. (LogCluster, Meeting Minute, 26.2.19, South Sudan)

Most interviewees acknowledge the cluster lead as a thought-guide and resource provider aimed at addressing community needs. The HOs expect the cluster lead to 
aggregate information and provide a common understanding toward operational challenges, despite potential power struggles among HOs.

This is what I appreciate: in case the cluster is not active, then you have to create the supply chain on your own. That's why it's great to have all that information already available from WFP... Yes, I think there is competition, but I think especially with the cluster, the system is not taking this away. But at least it's streamlining this by saying "we are focusing on priorities set by humanitarians or the coordinators." It ensures the needs to be addressed. (Participant 11; Quote 3)

\subsection{3 | Resource struggles}

Although HOs and their representatives appreciate the benefits of working together in the cluster, scarce resources such as donations curtail the willingness to coordinate with other outfits under the cluster lead's guidance. The following quote illustrates the salience of available resources:

This really depends on the pie, the exchange of information. If the pie is big enough, then the flow is rather existent. If not, then information is not shared. No, I am convinced even very small ones then say "no, we better keep the two trucks for ourselves or these resources" instead of losing them in the whole cake. (Participant 8; Quote 4)

Resource distribution further exacerbates conflicts and confrontations spawned by scant resources. Consider the logistical challenges experienced during the Syrian crisis due to lack of funding:

Airlifts from Damascus to Qamishly continue as Nusaybin border from Turkey is still closed. However, due to funding constraints as of 14 January, rotations have been reduced from 3 to 2 flights a day, and the second aircraft previously brought in to increase capacity will be released by 19 January. (Meeting minutes, Antakya (Turkey), January 16, 2017)

Unsatisfied by the cluster lead's decisions, HOs may confront the cluster staff in charge, who then defend themselves as having acted as neutrally and transparently as possible, as the example below illustrates.

In January 2017, I traveled to Turkey [...] and one of the partners very emotionally accused us of not supporting operations through airdrops. So, I tried to explain. But those partners felt betrayed by us. So, there would be moments like this, as I say. We would get accused for political reasons that we didn't take part, that we were not standing up to the government, or that we are not prioritizing this over that. So, there are moments where we have to be very careful, subtle with our responses. And the best way to do that ... is to be honest and frank to our partners. We have to tell them why we are not able to do it, and then we always must present ourselves in a way not partial. We are neutral. (Participant 17; Quote 5)

\subsubsection{The cluster lead's roles}

Despite its efforts to act as an "honest broker," HOs often cast suspicion on the cluster lead due to the latter's dual role and "double-hatting staff" (Inter-Agency Support Branch, 2020, p. 5) - in terms of both leading the cluster and operating as an $\mathrm{HO}$ running its own disaster operations. Being active in these operations makes the cluster lead appear to be holding an interest in the cluster's resources, and leading the cluster could facilitate leveraging those resources. The respective minutes corroborate this observation. For example, the lead in Pakistan performed a dual role as it was running large food operations itself.

WFP [the Cluster Lead] started food distributions yesterday (1 August) in Khyber Pukhtunkhwa (KPK), reaching about 500 families. The initial plan is to reach 3,000 families immediately and reach 35,000 families over the course of the next month. Distributions were focused in three regions in KPK namely Charsadda, Nowshera, and Peshawar. The scope of the distributions can be expanded as the situation requires and access to other regions becomes available. (LogCluster, Meeting Minute, 02.8.10, Islamabad)

This dual role becomes political when the cluster lead seems to assign resources unfairly, for example, favoring itself as an active aid agency, securing resources for itself, channeling the exchange with donors, or prioritizing its own operations over others. Conflicts of interest arising from the cluster lead's dual role hamper coordination. In the worst cases, people questioned the utility of cluster meetings to such a degree that they abstained from future meetings or joined alternative coordination groups.

I think the major issue is that the biggest actor, being WFP in terms of capacity, has two heads - the head of being the partner with the biggest capacity, as well as the lead agency for the LogCluster. And that makes an area of ambiguity, with a major conflict of interest toward donors, toward the community, where this is not solved and reduces the robustness of the 
initiative. For example, for the NGOs, one of the consequences is building another group. We have built another group where we are all at the same level ... with the same power, and we are really ... pooling resources, sharing information, partnering, etc. [...] In LogCluster, it is very politic[al], and there is a big conflict of interest between the WFP and the LogClusterit's really blocking the power of what could happen. (Participant 1; Quote 6)

They don't want to come ... they see the outcome of such meetings as negative. It's a waste of time when people, certain people, are dominating the coordination meetings. (Participant 17; Quote 7)

One key informant who formerly coordinated cluster meetings explained the apparent ambiguity when the cluster lead also serves in disaster operations as an active aid agency. Here, the meeting agenda and operations priorities were often perceived to be in line with the cluster lead's strategic directions:

NGOs having a logistic capacity to put in the basket is quite limited. So, I think the fact that many of the resources in those operations are from WFP_it's true; it's a fact. So, I think the way WFP favors itself is prioritizing their items over others, but also using the LogCluster as a way to influence the strategic direction of the operation with partners, like the government, like the case in [a country]. So, it's more about not completely taking on board the strategic vision of the partner than a resource materials perspective. (Participant 12; Quote 8)

On the positive side, when the cluster lead's behavior is not perceived as pursuing its own agenda as an $\mathrm{HO}$ or prioritizing its own operations above others', it is viewed as neutrally facilitating and coordinating the information and resource exchange among cluster members, providing them with resources. Consequently, coordination is improved. The quote below shows how the staff on the ground (i.e., the cluster coordinators) can subordinate the lead's dual role and behave more like facilitators.

WFP obviously staffs the cluster, and there is this thing around making sure, in an emergency response, it's not just a WFP response of that country - it has to be independent decisions for the good of the partners. [... when] you're a WFP staff member and you're a cluster coordinator, if you behave if you were completely independent from WFP, then you are very well respected. If you behave as if you were still into the call of WFP's logistics, then it causes issues because the other partners will know "ok, you're just putting WFP first." So, it's more ... the behavior of the [lead]. (Participant 10; Quote 9)

\subsection{5 | Swift trust}

Finally, the cluster lead's roles affect members' swift trust in the cluster during meetings. Swift trust describes the need to develop trust ex-ante in temporary settings and is a collective form of managing issues of vulnerability, uncertainty, risk, and expectations (Meyerson et al., 1996). In this study, swift trust refers to HOs rapidly forming trust or mistrust based on the lead's behavior. As such, the dual role evokes swift mistrust. One interviewee summarized this issue as follows:

There is still a substantial distrust between the NGO and the UN scene, also because of the dual role the UN is playing-sometimes a donor, and sometimes an implementer. (Participant 16; Quote 10)

Avoiding a dual role, however, fosters swift trust. A staff member noted that not running any operations reduced ambiguity regarding the lead's role and helped build swift trust:

There are not so many questions about the trust and where my agenda was. I didn't have any agenda; I didn't have any operations, and it really smoothed things down. It was ... making everybody on the same level. We all had one specific thing you could offer to each other, and therefore it was very clear there was no ambiguity $[\ldots]$ it was a level of trust. (Participant 12; Quote 11)

Next to trust issues concerning the cluster lead's dual role, we also observed differences in vocal behavior between international and local HOs. Local agents are often underrepresented in cluster meetings due to low participation rates and the fact that they happen to be the most tacit group. According to international aid workers, local HOs become silent when they feel intimidated amid the environment of experienced international aid workers who verbally dominate the meetings.

Especially when you were a national organization and suddenly you're surrounded by all these ex-pats who have done this ten times before, and they all know each other and you have some information, but [not] sure I want to [raise] my hand and speak. You know it's an intimidating environment, and it's something ... we are really trying to address in terms of how the right information comes up and goes through these scenarios. (Participant 2; Quote 12) 
At the same time, international HOs are careful in choosing their local partners since they fear that local organizations might be affiliated with political or dubious parties that could tarnish their images. Therefore, they rather tend to coordinate and forge swift trust with well-known international HOs.

I would say there is a sense of trust, and ... it's definitely more between the well-known names: let's say World Vision and UNICEF want to cooperate. There won't be any red flag, or it won't look fishy $[\ldots]$ when dealing with local organizations ... not to say that it's not trustable, but probably you will take that contact into consideration - that this corporation was a local organization - and how it affects the image and also ... operations. (Participant 18; Quote 13)

\subsubsection{Information accuracy}

As a consequence, internationals rely on their experience while widely neglecting local first-hand information. This is unfortunate given the overall acknowledgement that local information is needed to develop a common understanding of the situation.

Local entities [are] crucial to determine what way and how quickly things can be distributed and I think that recognition that we need each other, a chain a keyword in supply chain management that we need to link the various actors all together in order to establish the chain of delivering, that concept is really well understood and supported. (Participant 11; Quote 14)

The cluster accordingly calls for enhancing the integration of locals and acquiring accurate information by reaching out to locals before and during meetings:

So there is disparity. But again, a good cluster coordinator on the ground will mitigate that by reaching out to the local NGOs. That is something ... the cluster is not doing well. They started to invite local NGOs to the global cluster meeting, and that was great. [...] There has to be a lot more [of] this outreach and understanding. (Participant 15; Quote 15)

\section{5 | A grounded theory of interorganizational dynamics in humanitarian cluster meetings}

Our inductive approach provides in-depth descriptions of the interorganizational coordination during humanitarian cluster meetings, which include organizations and their representatives. Holistically interpreting the emergent concepts and their relationships, it reveals the simultaneous tension between coordination and resource struggles rooted in resource disparity, ambiguous roles, and swift trust. HOs' dependence on the cluster for resource allocation pits them as rivals to the lead's own HO activity. While HOs expect cluster resources to mobilize in service to HOs, the dual role of the cluster lead as a facilitator and an active HO disrupts these expectations when the lead appears to favor its own agenda. While resource transfer by the cluster lead may prove effective in addressing the needs, conflicts of interest undermine the trust and subsequent coordination among the cluster and HOs. In contrast, we observe that the cluster staff that did not enact a dual role during the cluster meetings, but acted as pure facilitators, fostered trust and coordination. Our grounded theory echoes evidence from power research that documents resource struggles when resources are limited (for a review, see Greer et al., 2017). Unequal power relations and the self-interest reflex to control collaborative agendas pose a permanent challenge to successful collaboration (Vangen \& Huxham, 2003a, 2003b).

While operations management literature has stressed the importance of mutual trust (Altay \& Pal, 2014; Brinkhoff et al., 2015; Moshtari, 2016; Özer et al., 2018; Özer \& Zheng, 2017), our findings further unearth the factors shaping that trust. More specifically, our emergent themes replicate swift trust formations in rapid teams (Mayer \& Davis, 1995; Meyerson et al., 1996; Schiffling et al., 2020; Tatham \& Kovács, 2010). Our first- and second-order themes present specific categories based upon which meeting participants categorize and consequently do or do not trust each other. Importantly, we add to extant research that leadership styles shape swift trust (dual role vs. pure facilitator), given the resourcedisperse context of cluster meetings. Specifically, the dual role of the cluster lead breeds swift mistrust and resource struggles among cluster members. Moreover, local HOs and their information remain widely excluded in cluster meetings due to feelings of intimidation that paralyze locals and generate swift mistrust among international HOs.

As a consequence, local first-hand knowledge in the cluster emerges as an essential, yet neglected element for accurate needs assessments and effective disaster response. The distinctiveness of locals seems to exacerbate the resource disparity between local and international HOs with regard to logistical and information resources (Frennesson et al., 2020). In sum, localization, information accuracy, and swift trust levels all emerge as important boundary conditions for us to examine.

The inductive approach thus granularly converges research on swift trust, roles, and coordination whose generalizability to the extreme context of humanitarian operations and cluster meetings remained contestable. As such, and in distinction to previous studies, we identify neutral leadership roles (pure facilitation) as a central lever to swift trust and coordination in resource-disperse and high-pressure environments such as clusters. We further highlight the issue of swift trust categorizations that lead to the exclusion of certain meeting groups. 
Despite the rich insights and implications, our inductive study has three important limitations. First, our sample lacks a counterfactual where the lead is absent. This comparison is relevant to build on prior research, which has advocated having a cluster leader (Altay \& Pal, 2014; Tomasini \& Van Wassenhove, 2009). Second, we also need to demarcate the boundary conditions of our theory. The nonlinear and complex dynamics among HOs during disaster response makes observing the different boundary conditions difficult. For example, our inductive study captures swift trust issues between internationals and locals, posing challenges to accurate needs. However, these findings are mostly based on the descriptions of internationals because locals are certainly underrepresented in the cluster (900 meeting minutes across 45 countries revealed only 1.57 local meeting participants on average [with a standard deviation of 0.63]) as well as our sample. Third, we also recognize the challenges in objectively quantifying the performance of humanitarian relief efforts in the field. Consider the possibly biased perceptions of cluster members, who feel threatened by the cluster lead's dual role ostensibly purloining resources that they also need, therefore possibly overestimating the dual role's detrimental effect. To address these limitations and deepen the findings, we thus developed an ABS. This model specifically compares absence and presence of a cluster lead, the lead's roles, and their impact on performance under a variety of key boundary conditions emerging from our theory: resource disparity, swift trust, and information accuracy/localization.

\section{4 | STUDY 2: AN AGENT-BASED SIMULATION MODEL OF THE LOGCLUSTER}

On the basis of Study 1, we built an ABS model to vary the cluster lead's role in coordinating information and resource exchange during its meetings. Interorganizational relationships are complex. Prior research has advocated the use of ABS as a powerful theory-building tool to capture complex nonlinear interactions (Sting et al., 2019). ABS also serves as a computational laboratory to investigate "what if?" (Burton \& Obel, 2011). Specifically, we use ABS to augment the theory emerging from our inductive analysis by systematically testing the effect of a dual role versus pure facilitator on aid delivery while defining its boundary conditions. Another handy technique is using system dynamics to simulate scenarios with high levels of abstraction by enlisting aggregate constructs (Borshchev \& Filippov, 2004). However, our aim is to model $\mathrm{HO}$ behavior in lieu of aggregating them as a system construct. Another technique, discrete-event simulation, focuses on entities, but these are usually cast as passive objects (Borshchev \& Filippov, 2004). Organizations in the cluster meetings, however, actively learn from and act on feedback. ABS permits both aspects: a detailed focus on heterogeneous organizations as our active unit of analysis, but also HOs able to learn by following specified behavioral rules.

\section{1 | Model design}

We follow the "overview, design concepts, and details" protocol (Grimm et al., 2010; Urrea et al., 2019) to describe the model detailed below. The overview specifies the purpose, entities, state variables and scales, process overview, and timing. For each element, the related design concepts are explained regarding the basic principles, adaption, objectives, learning, interaction, stochasticity, and emergence. Finally, we specify details for parameter initialization, input data, and submodels.

\subsection{1 | Purpose}

The main insight our inductive analysis yields is the cluster lead's role in coordinating HOs. The purpose of our model is to explicitly assess different roles for the cluster lead. We define three roles:

(i) No involvement: The cluster lead neither facilitates coordination nor contributes resources. In this scenario, the cluster lead does not attend the cluster meetings and the cluster members cannot access the lead's resources.

(ii) A pure facilitator role: The lead is present at the meetings without any agenda. It serves as an information aggregator while retaining and offering the cluster lead's resources for cluster members' needs.

(iii) A dual role: The cluster lead is present at the meetings and acts as both a facilitator and an active $\mathrm{HO}$ allocating resources to reinforce its own agenda.

We investigate how these roles affect two outcome variables related to HO performance in disaster response. First, we measure the amount of needs met defined as the percentage of logistical needs that the HOs were able to satisfy ( $=$ fulfilled needs/total initial needs). These needs refer to logistics resources that depend on beneficiary needs. Second, we measure resource utilization to investigate how efficiently the HOs addressed the needs $(=1-$ remaining resources/initial resources). The maximum level of resource utilization of 1 refers to the case where the cluster uses all of its logistics resources needed to satisfy beneficiary needs.

\subsection{2 | Entities, state variables, and scales}

We model $N$ number of HOs, including international, local HOs, and the cluster lead. The percentage of locals is set by the parameter localization, $0 \%$ indicating no local involvement and $100 \%$ indicating only locals in the meeting. The HOs' aim is to meet needs with $M$ logistics resources across $R$ regions for a disaster. Examples of these resources include transportation assets, staffing, warehouse space, and so on. We thus represent needs (the demand posed by the disaster context) as a matrix with $R \times M$ dimensions. The agents are 
characterized by three state variables that align with the key boundary conditions to cluster performance as identified in our qualitative study:

1. Resource disparity: It captures the distribution of logistics resources across HOs. To compare resource utilization under different scenarios without loss of generality, we set the total amount of resources possessed by all HOs together equal to the total number of logistics needs. Here, HOs potentially have all the necessary means to address every need when coordinated effectively. Our results remain qualitatively similar when we simulate environmental conditions in the field such as resource scarcity (total resources underserving total needs) as opposed to surplus (resources exceeding total logistics needs). We array $\mathrm{HO}$ power as an $N \times M$ matrix. In alignment with Study 1, there are stark resource differences from cluster lead to HOs. We capture these differences in a resource disparity variable ranging from $10 \%$ to $90 \%$ to reflect the concentration of resources by the cluster lead. Low disparity indicates a more equal distribution of resources across HOs and the cluster lead. High disparity indicates a cluster lead having disproportionately more resources.

2. Swift trust: It embodies a square matrix of $N \times N$ possible relationships among HOs where 1 indicates a connection from one $\mathrm{HO}$ with another and 0 is no relationship. When HOs are linked, their swift trust allows them to reach out and share resources with each other. Our qualitative analyses reveal that swift trust varies across disasters and depends on HO's past experiences. For instance, some HOs may have worked together in other disaster programs or trainings, during which they built trust. Local HOs are often unknown: One interviewee noted "a sense of trust which is definitely more between the well-known names" (Participant 18; Quote 16). We operationalize this difference by the parameter "swift trust"- the number of active connections divided by the total number of possible connections. For instance, a swift trust density of $10 \%$ means that only $10 \%$ out of all possible ties among participants exist at a cluster meeting's onset. Connections among HOs are randomly assigned. We let all HOs be initially connected to the cluster lead since they participate in the cluster and know the cluster lead as a last resort. Yet, interactions during humanitarian operations may damage swift trust. One interviewee noted that "Sometimes we try to work really hard to have this level of trust with a lot of the partners and it's a super fragile trust. [...] I have seen cases where trust was almost gone based on misunderstanding." (Participant 16; Quote 17). Our simulation accordingly considers swift trust density to be dynamic, such that HOs' actions might hurt swift trust (see process and timing below for details).

3. Information accuracy: Information is key to successful coordination. Since HOs imperfectly know their regions' logistics needs, we randomly assigned each agent an infor- mation accuracy about needs from a normal distribution with a mean of 0 and 0.1 standard deviation. Imperfect knowledge about a region's logistics needs implies that the more regions the HO handles, the less accurately it can assess those needs. With an increasing scope of regions, international HOs, for instance, must allocate attention among a large number of areas, leading to faulty assessments. Conversely, local HOs with a smaller and more specialized scope can focus attention on fewer regions where they can acquire deep local knowledge to more accurately assess logistics needs. This modeling choice is grounded in practitioner reports such as the Humanitarian Policy Group (2015). Our informants, too, distinguish local HOs as having "huge potential" and a "network of information" (Participant 8; Quote 18) in "small interventions" (Participant 21; Quote 19). Accordingly, we model the number of regions that one HO handles using a regional scope parameter as a percentage of total regions. This parameter determines the percentage of total regions that one international $\mathrm{HO}$ focuses on which is set to $50 \%$, whereas local HOs are assigned $10 \%$ of the regions. Since the cluster lead as meeting facilitator must monitor all available regions, present in the field or not, its regional scope is $100 \%$. Each $\mathrm{HO}$ experiences a noise that is the product of its regional share multiplied by a random number drawn from a normal distribution that is centered at 0 with a standard deviation of 0.1 . Finally, this noise constitutes how accurately the $\mathrm{HO}$ is informed about the logistics needs. Here, the more regions the $\mathrm{HO}$ engages in its disaster response (i.e., large regional scope), the less accurate its information is regarding the logistics needs for each region:

It does get tricky if WFP does not have somebody on the ground ... [as] we found in the response in Yemen - the WFP didn't have somebody on the ground and [name of organization] did, so we [got] a lot of information. (Participant 15; Quote 20)

Finally, interview participants described HOs with larger regional scopes (i.e., internationals) as possessing more logistical resources. Accordingly, we distributed resources proportional to HOs' share of regions (HO's regional scope/total of regional scopes over all HOs). Consequently, locals receive fewer resources than internationals. There is thus a tradeoff between higher information accuracy on the side of locals and greater logistics resources on the part of internationals. That said, resources can be invested in and thus help to acquire higher information accuracy. That is, by sharing logistics resources with an $\mathrm{HO}$ that yields higher information accuracy, one retrieves the HO's information (see process and timing). The ABS parameters are summarized in Table 2, which further shows how the simulation parameters align with the aggregates from the qualitative study. 


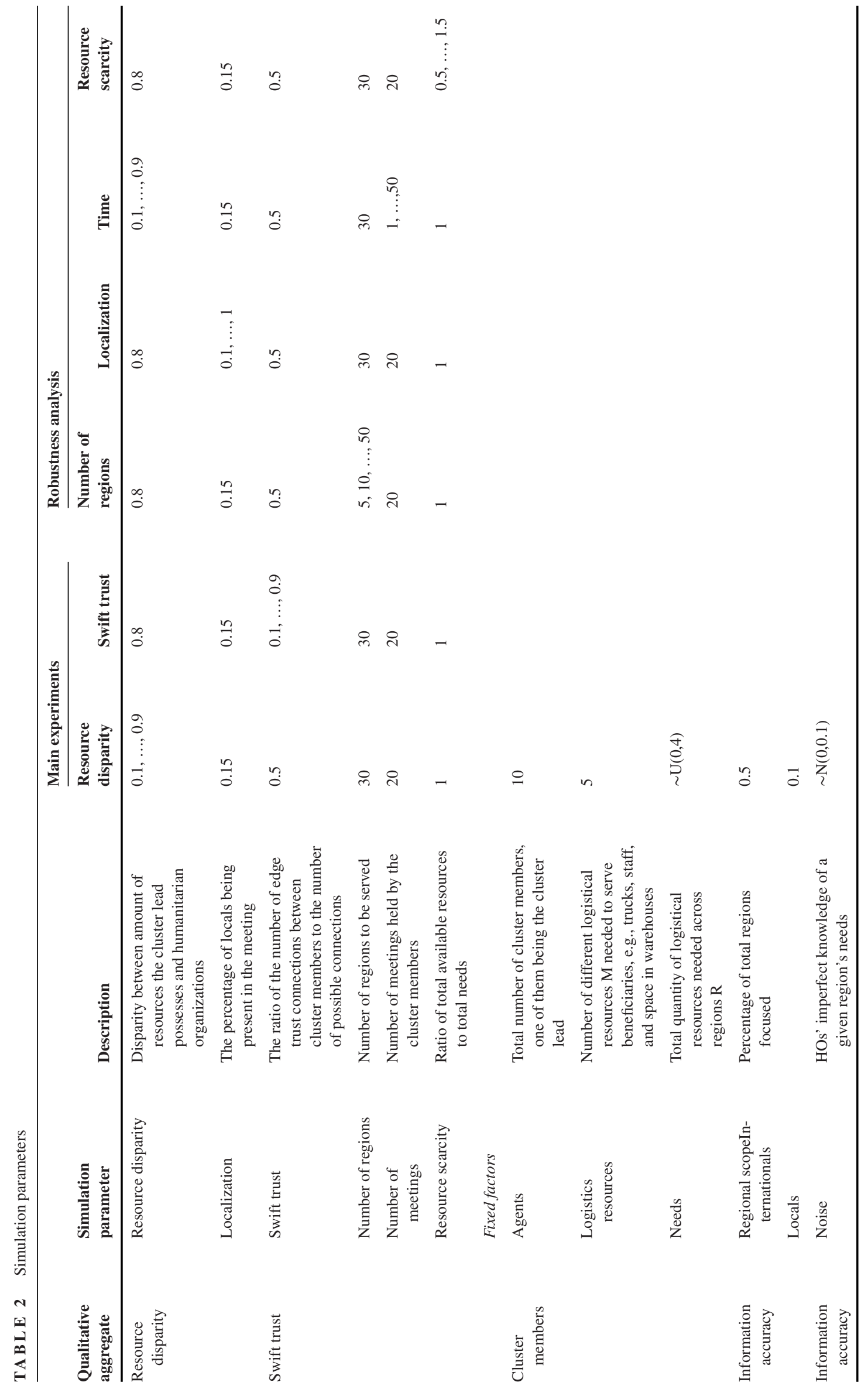




\subsection{3 | Process overview and timing}

Figure B in the Supporting Information summarizes the simulation process, agent behavior, and decision rules. At the onset of the simulation, each $\mathrm{HO}$ focuses on regions within its scope (i.e., regional scope) and prioritizes the region with the most logistics needs based on its information. In line with the interviews, the cluster lead facilitates information sharing across the HOs regarding their needs assessments.

After the official information exchange between the cluster lead (if one is available) and members, each HO has the opportunity to reach out to a partner to ask for resources. As mentioned by our informants, the process starts with the cluster lead. To rule out order effects, we randomized the speaking order. As a robustness check, we modeled speaking order based on each HO's perceived needs for logistics resources; the $\mathrm{HO}$ believed to have the highest needs speaks first, and so on.

If the HO has enough resources, it covers the needs in the prioritized region by itself. If the HO lacks resources to fulfill the logistics needs in the selected region, it reaches out to another $\mathrm{HO}$ within its swift trust network. This modeling choice emerged from our interviews where the interviewees explained that they reach out to participants they know, the so-called "network of trust" (Participants 16 and 18; Quote 21). That is, HOs selectively contact partners to increase the probability of receiving the needed resource: "There are people from whom I expect something and where I can say, ok I expect you to deliver tents because I heard many refugees are coming. Do you have them, will you get some?" (Participant 6; Quote 22). However, partners may not always chime in to offer help; instead, they keep resources for themselves. For example, Participant 8 noted this competitive element: "Even smaller ones then say they hold their resources in, we keep the two trucks for tomorrow for ourselves, before they get lost in the cake" (Quote 23). We capture this insight in our model as follows: When a partner has a different priority region, it withholds the requested resources. Consequently, the requesting $\mathrm{HO}$ updates its swift trust by cutting its tie with that partner. That is, the agent cuts ties with a partner perceived to possess the required resources but who withholds them due to different priorities. Participant 3 described this as a reciprocity rule: "I will trust you; if you helped me in previous missions or this time, then I will also help you" (Quote 24). Participant 5 stated, "It cannot be a one-way street, it's always a two-way street" (Quote 25). Furthermore, updating the swift trust network helps the HOs learn that the partner does not share priorities and that they need to reach out to other partners in the next round to mitigate the risk of being disappointed again. This rule replicates previous research on swift trust where swift mistrust is described as a protection and risk mitigation mechanism, no matter the potentially converging priorities in regard to regions or resources (Özer \& Zheng, 2017; Schiffling et al., 2020). It is also difficult to build or repair trust in the short life circles of disasters (Kim et al., 2009; Kramer \& Lewicki, 2010; Lewicki \& Brinsfield, 2017). Coordinators described it as follows:

Sometimes we try to work really hard to have this level of trust with a lot of the partners and it's a super fragile trust. [...] I have seen cases where trust was almost gone based on misunderstanding. (Participant 16; Quote 26).

Reciprocity thus also applies to interactions between a cluster member and the cluster lead. Members who feel that their allocations do not align with their expectations will shun the cluster lead:

Let's be frank ... work goes badly when [the] UN has shared with the UN and ... international HOs got frustrated and set up their own donation group and worked together. (Participant 2; Quote 27)

For the NGOs, one of the consequences is building another group. We have built another group where we are all at the same level ... with the same power. (Participant 1; Quote 6)

Our results remain qualitatively similar when we allow the HOs to go back to the cluster lead regardless of the previous experience. This is because our simulation starts with all HOs having swift trust with the lead at the onset of the simulation.

When a partner has the missing resources for the same priority region, it shares the requested amount. Here, the provided resources are subtracted from the partner's resource endowments. Both the recipient and partner update their information by deducting the amount of pooled resources from their information about the region's needs. Finally, the pooled resources are also subtracted from the actual needs.

This process is repeated for 20 time periods, after which the met needs and utilized resources are calculated. To determine this time parameter, we measured the median number of meetings for the HOs to converge, finding that the convergence is achieved before 20 meetings (see Figure $C$ in the Supporting Information). We ran 1000 simulations to filter out the random noise.

\subsection{4 | Submodels}

We compare three main scenarios: (i) no involvement, (ii) $a$ pure facilitator role, and (iii) a dual role. In the dual-role scenario, the cluster lead facilitates information exchange and delivers aid to its own priority regions as an active HO. First, the cluster lead organizes an information briefing before the resource exchange by sharing its information about logistics needs with connected partners. Here, the cluster lead and partner share and update information regarding needs assessment. For instance, if the cluster lead feels that 
region $\mathrm{A}$ needs five items and shares this with a member assessing only one needed item, each updates its information to the average of three. Next, the cluster lead advances its own agenda as an active $\mathrm{HO}$ in the disaster response by selecting a priority region where it delivers aid like other HOs. In contrast, the pure-facilitator scenario depicts a cluster lead not serving a region as its own HO, who organizes an information update before the resource exchange. One cluster coordinator illustrated this role as follows: "our main focus should be information and coordination" (Participant 16; Quote 28). While a cluster lead does not prioritize and serve a region, it can behave as a potential partner, retaining and offering its resources to support any request for cluster resources in any requester's priority region. In the "noinvolvement" scenario, the cluster lead and its resources are withheld from disaster response. Here, the lead is replaced by another HO to keep the number of agents in the simulation constant $(=\mathrm{N})$.

\subsection{5 | Initialization}

We used cluster meeting minutes to parameterize our variables and to conduct sensitivity analyses by varying the parameter values. We observed an average of 10 meeting participants during the initial 20 meeting minutes following a disaster in 45 countries (900 meeting minutes in total). Accordingly, we included $10 \mathrm{HOs}$ in our model. We confirmed that all simulations converge in 20 rounds (see Figure $\mathrm{C}$ in the Supporting Information). We further used the meeting minutes to calculate how many local HOs participated in the cluster meetings (localization). We found only 1.57 locals on average (with a standard deviation of 0.63) taking part in cluster meetings. Therefore, we set the localization (i.e., percentage of local HOs involved) to $15 \%$. We set the initial regional scope parameter for international HOs (the fraction of total regions per $\mathrm{HO}$ focus) to 0.5 so that they cover half the available regions. At the same time, locals were assigned to $10 \%$ of the regions.

Although meeting minutes clearly indicate needs for different resources across regions, they do not provide a clear indication of how many resource types and regions embody a typical disaster situation. Without loss of generality, we assigned five different resources across 30 regions in the main analysis. To start each simulation run, we randomly generated the needs for logistical resources across regions with resources allocated to HOs per the resource disparity variable.

Organizations were also randomly connected to each other using the swift trust density parameter. Since trust varies across disasters, and HOs and their representatives may enter a field without knowing most others, we set swift trust to $50 \%$. For each parameter, we analyzed robustness by varying one value while fixing the others in alignment with the main experiment (see Table 2). The simulation code is available on the Open Science Foundation repository: https://osf.io/ w953p/?view_only=4000ee02d085479fa2320f113c0cc0c6.

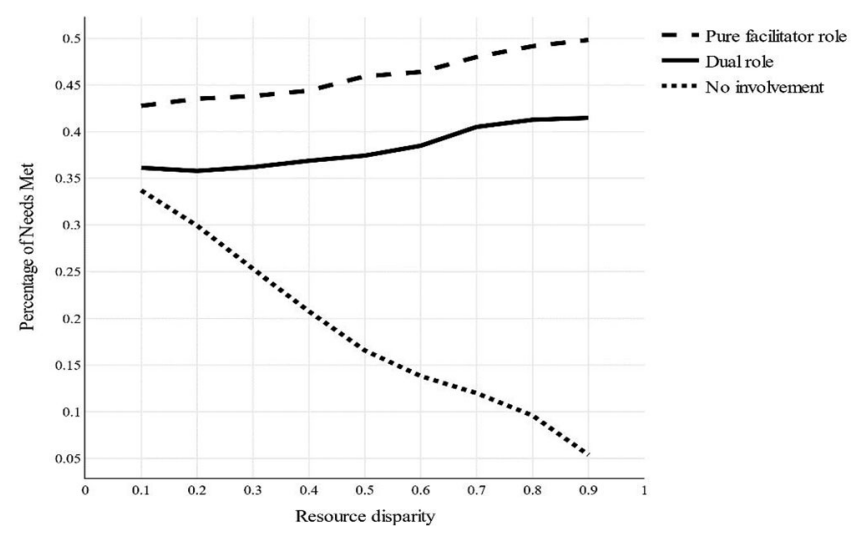

F I G U R E 1 F Percentage of needs met as a function of resource disparity

\subsection{6 | External model validation}

To supplement our theory emerging from the inductive study of LogCluster, we enlisted expert feedback from the LogCluster on the design, proxy variables, and parameters in the simulation. In particular, the feedback focused on how resources are exchanged among partners (requesters devoting all their resources and partners covering the deficits) and on conventions such as the cluster lead opening sessions by sharing information. We also validated that our choice of parameters made sense. Three meeting coordinators disclosed that most meetings featured a high resource disparity $(80 \%)$ between the cluster lead and the HO group. External model validation tuned model factors such as resource allocation, connections, and procedures to reflect practice as closely as possible.

\section{2 | Results}

Figure 1 compares the different roles of the cluster lead (i.e., dual role, pure facilitator role, and no involvement) in relation to resource disparity (i.e., the concentration of resources in the cluster lead). The $\mathrm{Y}$-axis plots the percentage of logistics needs met by the HOs versus resource disparities on the $\mathrm{X}$ axis. When the HOs and the cluster lead have equal amounts of resources, "no involvement" performs only slightly worse than the dual-role scenario. This difference can be attributed to the fact that the cluster lead retains its resources under the no-involvement scenario, thus leaving fewer resources for the cluster. In fact, the downward sloping line of the noinvolvement case reveals that greater resources kept by the cluster lead end up satisfying fewer HO needs. This finding supports the advice in prior research to enlist a cluster lead in humanitarian operations (Altay \& Pal, 2014).

Figure 1 also depicts the pure facilitator role scenario outperforming the dual role. Two mechanisms underlie this result: (i) a pure facilitator role maintains swift trust within the cluster and (ii) it allots resources more efficiently. First, a cluster lead with a dual role may prioritize and serve 


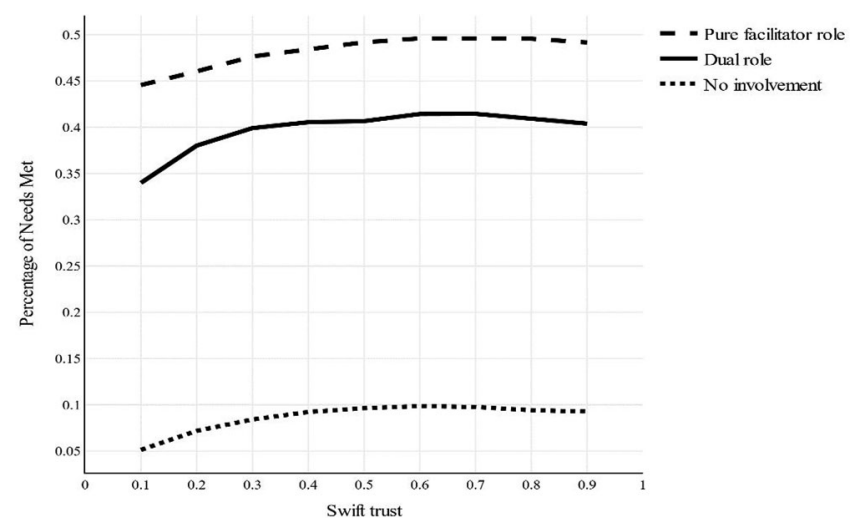

F I G U R E 2 Percentage of needs met as a function of swift trust

regions based on its own noisy assessment while taking these resources away from organizations with more accurate information about the logistics needs. Meanwhile, it may only support requests from HOs with overlapping priorities. When a cluster lead's prioritized regions differ from those for which HOs request aid, this misalignment damages the swift trust between a requesting $\mathrm{HO}$ and the cluster lead. In contrast, a cluster lead with a pure facilitation role does not favor a region and prioritizes resources in terms of cluster members' logistics needs, which avoids alienating HOs. Restoring resources for organizations such as locals with more accurate information enables the pure facilitator to build synergies with these organizations. That is, it not only provides them with logistical resources, but also gains insight into their accurate need assessments.

To illustrate this point, we varied the level of swift trust density in Figure 2.

Here, a gap clearly favors the pure facilitator over the dualrole scenario as swift trust increases. If there are too few swift trust ties, then partners barely exchange resources. The benefits of swift trust saturate after a threshold because HOs waste resources when they have incomplete information about the actual logistical needs. To illustrate, imagine a dense cluster yielding widely inaccurate information: Those partners reaching out to each other and the lead quickly exhaust the cluster's resources.

Shining more light on the mechanisms driving the purefacilitator's superior performance, Figure 3 plots the percentage of swift trust ties that remained at the end of a simulation run ( $Y$-axis) versus resource disparity ( $X$-axis), with 0.5 set for swift trust in the beginning of the first meeting. Figure 3 shows that a dual role loses more ties across all degrees of resource disparity than a pure facilitator. HOs quit partnerships more frequently when they possess more resources. To understand this effect, recall the rule that an agent cuts ties with a partner perceived to possess the required resources while withholding them under different priorities. Under low resource disparity (cluster members having similar amounts of resources), cluster members are more likely to reject each other's requests due to misaligned priorities, resulting in cut connections. Under high resource disparity, the cluster lead

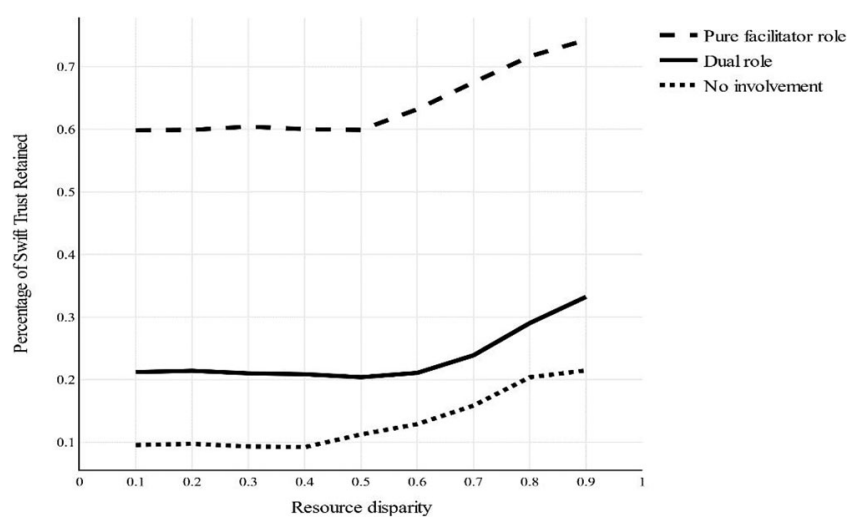

F I G U R E 3 Percentage of swift trust retained at the simulation run end as a function of resource disparity

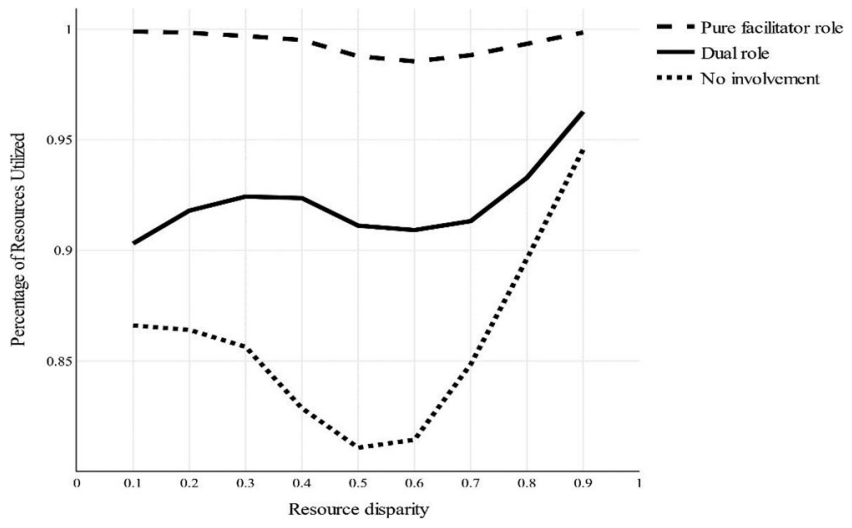

F I G U R E 4 Percentage of resources utilized as a function of resource disparity

has way more available resources than HOs. Partners thus maintain ties with each other because they lack resources they could share to meet field needs. When the cluster lead acts as a pure facilitator that unconditionally supports partners' requests, there are fewer ties broken between the cluster lead and partners. High resource disparity thus averts resource struggles among HOs by defining a central power-holder that makes resources accessible to everybody and strengthens swift trust (see Figure 3).

Second, the cluster lead with a pure facilitator role allocates resources more efficiently. Notably, when the cluster lead denies HOs' requests despite having the resources (as evidenced by its allocation of resources to its own choice regions as active $\mathrm{HO}$ ), the HOs cut ties with the cluster lead. The cluster lead's isolation then curbs its ability to update its information about logistics needs, and the result is inefficient resource allocation. In contrast, a pure facilitator maintains a swift trust that sustains information and resource exchange among partners and the cluster. Illustrating these arguments, Figure 4 shows a lower percentage of resources used efficiently when a cluster lead plays a dual role versus pure facilitation. It also documents less resource utilization and more waste when resource distribution is less concentrated under the dual-role and no-involvement scenarios. Since fewer swift 


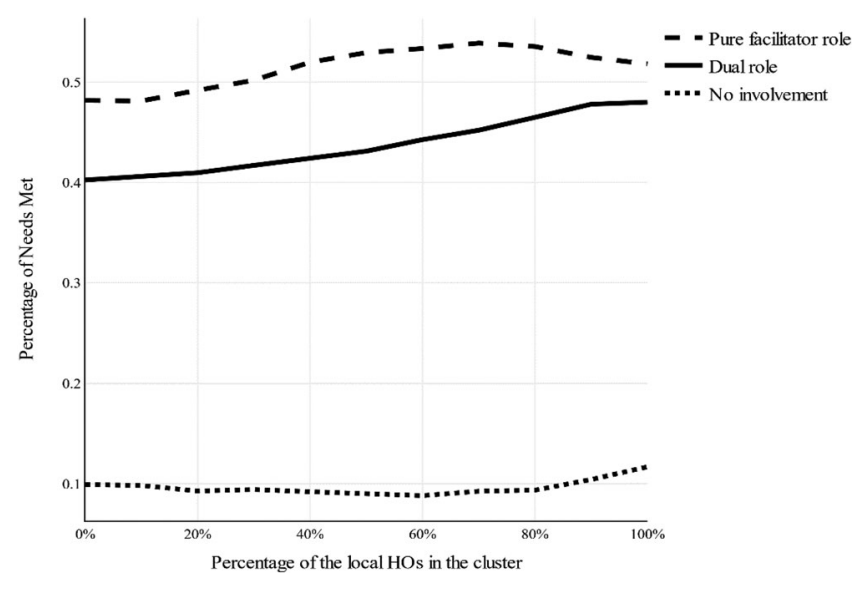

F I G U RE 5 Percentage of needs met as a function of local humanitarian organizations (HOs) involvement

trust ties remain in the dual-role and no-involvement scenarios when resources are allocated equally (Figure 3), there is also less resource exchange (Figure 4). In contrast, the pure facilitator uses available resources efficiently.

\section{3 | Boundary conditions and sensitivity analyses}

The model allowed us to also analyze the robustness of our findings by investigating several boundary conditions presented in Study 1. First, we examined the effect of cluster localization, that is, percentage of local HOs involved. Figure 5 shows that the more local HOs involved in a cluster, the higher the performance. This finding underscores the importance of adopting a local focus and integrating local knowledge to better assess logistics needs for affected regions. By engaging more local HOs (i.e., those with a smaller regional scope), cluster members (international HOs and cluster leads, specifically) can acquire accurate information and improve their aid delivery. Furthermore, locals can leverage their information for aid delivery if they are not dominated by internationals during meetings and the pure facilitator provides them with cluster resources.

Second, we analyzed how the number of regions affects the percentage of logistics needs met. The divergence of prioritized regions among the HOs and cluster lead will logically increase the number of regions. Figure D in the Supporting Information confirms that more regions lead to cluster underperformance. This pattern makes sense when considering that a large number of regions increases the difficulty of coordination efforts, as well as the risk of poorly assessing logistics needs. However, a cluster lead serving as a pure facilitator yields results that are superior to those under the dual role.

Third, rather than assuming cluster resources match the total amount of logistics needs, we investigated how resource scarcity affects our results by varying total available resources from $50 \%$ (i.e., scarce resources) to $150 \%$ (surplus resources) of total needs. Not surprisingly, the positive-sloped lines in
Figure $\mathrm{E}$ in the Supporting Information show fewer needs being addressed by cluster members when resources are scant. Still, the pure facilitator role serves needs better than both the dual-role and no-involvement scenarios, regardless of resource scarcity.

\section{4 | ABS discussion}

Our findings both replicate and advance the insights emerging from Study 1. First, they echo prior research advising that a cluster lead should aid disaster response (Altay \& Pal, 2014). We simulated perceptions shared in the interviews to find coordination benefits in having a cluster lead. Second, we found that the cluster lead's dual role is widely less effective than a pure facilitator, despite allocating large amounts of resources as an active HO. The dual role's gains through active resource transfers do not outweigh the loss of swift trust it creates across cluster members. The pure facilitator thus satisfies more logistics needs during a disaster response, even during the first meetings when urgency is high and one might assume that the dual role's capacity for rapid resource transfer would better meet needs. Interestingly, we found that centralizing resources in the hands of a pure facilitator strengthens swift trust among cluster members and enhances performance - a contrast to assumed idyllic equality. That is, the pure facilitator can provide groups such as locals, which possess highly accurate information, with the resources they need for aid delivery and thereby improve the overall relief response. As such, our fourth finding is that localization and information accuracy drive performance, leading to betteraligned priorities, less resource waste, and more logistics needs met. A pure facilitator is thus best capable of building synergies with local HOs by exchanging accurate information and logistic resources with them, and thereby mitigating resource disparity between local and international groups.

\section{5 | DISCUSSION}

Coordination in the field is key to a successful disaster response. However, disaster response is characterized by uncertainty, urgency, poor information flow, and a panoply of conflicting stakeholders. Despite efforts to boost interorganizational coordination by establishing clusters, some disasters such as the Haiti earthquake became known as "coordination failures" (Altay \& Labonte, 2014). Our research investigates why coordination in humanitarian cluster meetings still fails by considering the specific roles that cluster leads might play. Our qualitative study from the LogCluster reveals that the dual role of the cluster lead acting as both a facilitator of coordination and an active operator can hamper the successful coordination of the cluster. In contrast, a pure facilitator, perceived as having no self-interest in directing resources for its own agenda, builds swift trust and improves cluster performance. HOs join the cluster to exchange information and benefit from its resources. However, when HOs see the 
cluster lead as an active HO favoring its own operations with cluster resources, they doubt the fairness of the cluster and the benefits of meetings. The disassociation of local HOs and their first-hand knowledge of the country and people ailing from the disaster further impedes response. To investigate the effect of a dual role versus pure facilitator compared to the absence of a cluster lead, we built an ABS. The findings confirm prior research regarding the advantages of having a cluster lead over its absence. The simulation results also show that pure facilitation outperforms the dual role in meeting needs. Additional analyses unearth the mechanisms underlying our results: namely, that pure facilitators maintain swift trust among cluster members, build synergies with locals, and achieve a more efficient use of resources by incorporating member views.

\section{1 | Theoretical implications}

Our study offers three contributions to humanitarian operations research. First, we challenge the recommendation that the mere presence of a cluster lead is sufficient (e.g., Altay \& Pal, 2014; Jensen, 2012; Tomasini \& Van Wassenhove, 2009), and instead reveal the importance of a pure facilitator versus a dual-role approach. A growing number of studies have called for investigations of leadership and group dynamics in the context of humanitarian operations, which is shaped by limited resources and a high pressure to perform (Altay \& Pal, 2014; Dubey et al., 2015; Gunasekaran et al., 2018; Pettit \& Beresford, 2009; Salem et al., 2017, 2019; Sankaranarayanan et al., 2018). Our findings show that it is not only the presence or absence of a cluster lead that matters for effective coordination, but also the quality of their leadership. In particular, a pure facilitator that supports meeting participants' agendas functions as a building block in mitigating resource struggles and improving performance. As such, our results echo evidence from behavioral research in resource disparity that resource differences ignite power struggles and impair group performance. Resource struggles loom large when resources appear limited and highly concentrated (Greer et al., 2017; van Bunderen et al., 2018), as in humanitarian clusters where the HOs widely depend on the cluster's resources. What is missing in this line of research is how organizations can mitigate these struggles through the leaders' actions. This is important because interorganizational relationships face an ongoing battle between the spirit of collaboration (embracing, empowering, involving, mobilizing) and collaborative "thuggery" (manipulating the collaborative agenda and playing politics) (Vangen \& Huxham, 2003a).

Operations management literature similarly argues for a large fourth-party logistics (4PL) provider, which simultaneously serves as integrator, decision-maker, infomediary, and resource provider (Abidi et al., 2015; Cezanne \& Saglietto, 2015; Win, 2008). In contrast, previous research has highlighted the difficulty of establishing trust between logistics providers and clients (Bealt et al., 2016; Hofe et al., 2009; Wang et al., 2020). Win (2008), for example, described con- flict of interests between 4PL and clients when third-party logistics (3PL) act as 4PLs. That is because 3PLs function as asset-based services (e.g., warehouse, transport) and may try to maximize the use of their own assets through decisions that are not always in the best interest of the client organizations. In humanitarian clusters, the conflicts do not necessarily emanate from increasing the demand for assets. Here, the cluster lead acts as an asset-based 4PL fueling competition when it is observed as setting priorities by favoring its own operations with cluster resources. Hence, our findings undergird the problems related to the cluster lead simultaneously enacting multiple roles.

The coopetition literature has closely examined such tensions emanating from the simultaneous cooperation and competition between HOs (Stadtler \& Van Wassenhove, 2016). Hoffmann et al. (2018) explicitly raised the need to further corroborate the antecedents of both cooperation and competition. As such, our study specifically highlights that leaders can avoid conflicts of interest, even in the case of resource imbalances. We find that pure facilitation can serve collaborative agendas, reduce resource imbalances and conflicts, and boost the performance of interorganizational collaboration. In fact, its positive effect amplifies further when resources are concentrated in the hands of a pure facilitator, since the clear hierarchical structure with equal resource access engenders optimal coordination.

Our second contribution corroborates swift trust's conduct as an underlying mechanism steering coordination in a multiparty and decentralized organized environment such as humanitarian clusters (Dolinskaya et al., 2011; Meyerson et al., 1996; Schiffling et al., 2020; Tatham \& Kovács, 2010; Toyasaki et al., 2017). One important recommendation for effective coordination is developing "relationship management capability" (Moshtari, 2016) through ensured reciprocal commitment and mutual trust. Mutual trust encourages HOs to share information and coordinate their actions (Brinkhoff et al., 2015; Özer \& Zheng, 2017). Importantly, we still do not know how swift trust can be sustained during the brief life cycles that typify field meetings. However, our theory of the cluster lead's role aligns with the research advocating swift trust in interorganizational collaboration. We show that swift trust may not be an exogenous characteristic of humanitarian efforts, but a dynamic shaped by the roles that the cluster lead enacts. This finding directs the current conversation from the importance of swift trust in interorganizational collaborations to its antecedents in resource-scarce contexts, as well as offers important guidelines on how to cultivate swift trust.

Along with pure facilitator support, cluster members are responsible for accurately assessing the logistics needs and making proper requests to avoid wasting resources. This finding leads to our third contribution: Cluster coordination can falter when neglecting local, first-hand information regarding affected regions. Altay and Labonte's (2014) case study of the Haiti earthquake reports that coordination failed because international players dominated the response while ignoring local HOs and their knowledge. For this reason, we draw on the swift trust theory, which argues that trust 
in temporary teams is developed along categorization processes (McLaren \& Loosemore, 2019; Meyerson et al., 1996; Tatham \& Kovács, 2010). Our inductive study deepens these insights by showing that international HOs often lack swift trust toward representatives from local HOs, especially those affiliated with political parties or that are not involved in prior disaster responses. Meanwhile, local HOs often feel intimidated amid experienced expatriates and hesitate to speak up in meetings. Yet, our simulation shows that local integration boosts performance. This finding aligns with a current trend in humanitarian research that calls for enhanced localization while emphasizing the importance of considering swift trust dynamics between local and international HOs (Berenguer \& Shen, 2019; Besiou \& Van Wassenhove, 2020; Frennesson et al., 2020; Lewin et al., 2018).

\section{2 | Limitations}

While we took advantage of a multimethod approach, our study has numerous limitations. First, we argue that cluster meetings are highly representative of coordination as a whole in humanitarian operations. However, one needs to bear in mind that cluster meetings represent an important, yet small piece of the whole picture. Future studies can expand the scope by combining insights from meetings and the field to explain coordination in humanitarian operations.

Second, our qualitative, inductive study is limited to the humanitarian relief efforts organized within the LogCluster. Given its purpose and mission as a central coordination platform, the LogCluster and its meetings serve as an appropriate context for investigating coordination in humanitarian operations (Besiou \& Van Wassenhove, 2020; Gralla et al., 2014). The context of the LogCluster offered rich insights into the interorganizational dynamics in cluster meetings. Considering the LogCluster's prevalent role in operations and study participants' multiple cluster memberships, these insights could be certainly extended to other coordination groups. Future studies may focus on validating and contrasting these findings across different humanitarian contexts that demand interorganizational collaboration.

Third, the disaster context merits added consideration. In some disasters, the cluster lead might experience very restricted logistical resources in the face of high demand for activating its own HO operations, thus justifying its enactment of a dual role and allocating cluster resources for its own theater. However, it could be that HOs possess the necessary skills, but not the means, to conduct disaster response alone, thus calling for a pure facilitator to neutrally assign the assets. Additionally, military assets might be involved in humanitarian operations (Besiou \& Van Wassenhove, 2020) or the military may even be coordinating the disaster response (e.g., Haiti). Given our finding that resources concentrated in the cluster lead benefit cluster performance, it would be valuable to know how the participatory cluster approach as investigated in our study differs from a more centralized military command style. Overall, future studies investigating the roles of cluster leads should distinguish disasters by type and the characteristics of involved organizations in terms of competencies versus operational means.

\section{3 | Implications for humanitarian practitioners}

In their strategy statement, the LogCluster states that "WFP hosts the Global Logistics Cluster support team in its headquarters in Rome. WFP also acts as a 'provider of last resort' offering common logistics services when critical gaps hamper the humanitarian response" (LogCluster, 2019). This mandate is rather broad and leaves field practitioners with ample discretion in how to enact it. In that vein, we warn against the cluster lead agency enacting a dual role as a coordination facilitator and an active operator. We offer evidence that ambiguity in the cluster lead's dual role impairs swift trust and resource utilization when a cluster lead is perceived as prioritizing its own agenda as an active $\mathrm{HO}$ over other $\mathrm{HO}$ aims. Practitioner reports on coordination also highlight the issue of double-hatting among cluster leads (Campbell, 2016; Knox-Clarke \& Campbell, 2015). In sum, a pure facilitator role for the cluster lead seems more beneficial for coordination. The cluster lead agency should separate its own agenda from cluster activities to focus its efforts solely on resourcesharing among partners.

This managerial implication also depends on the way cluster leads are designated. If HOs with large operations are preferred as resource providers and cluster leads, it might reinforce systemic conflicts of interest. To safeguard neutral resource-sharing, the cluster system should assign cluster leads that are unencumbered by operations where possible. If cluster leads with dual roles are designated, double-hatting staff should be trained to separate agendas and transparently account for how resources are allocated, enacting a dual role only when there are too few HOs in the meeting that know each other and collectively represent a too-narrow regional scope. Importantly, employees from the cluster lead agency that function as cluster staff should signal the prioritization of cluster members' logistics needs in meetings, given that the lead agency donates these resources to the cluster. It is critical for the LogCluster representatives to be transparent about how many resources WFP is offering to the LogCluster partners and how many WFP needs for their operations. Here, the cluster agency may benefit from clearly dividing its budgets in terms of cluster members' usage and its own.

A second notable takeaway concerns the insight raised by UN Secretary-General Ban Ki Moon at the 2016 Word Humanitarian Summit: namely, that "there is frustration on the part of governments and local organizations that struggle to be seen by the international community" (SecretaryGeneral of the United Nations Ban Ki-moon, 2016, p. 4). Field reports similarly stress that the neglect of locals and their knowledge poses a challenge to successful field 
coordination (Campbell, 2016; Knox-Clarke \& Campbell, 2015). The current situation thus calls for enhanced communication among international and local HOs. In light of our findings, meeting coordinators should support this endeavor by creating an environment where everyone feels safe to speak up and building synergies with locals (exchange information and logistical resources). Such a safe environment can, for instance, be fostered by frequent interactions and regular checks with locals to determine whether they feel safe in meetings, asking participants for feedback on delivery, and offering regular reminders of the joint objectives (Delizonna, 2017; Siemsen et al., 2009). Moreover, clear meeting structures and speaking assignments reserved for different organization types, especially locals, as well as translations to bridge language barriers, provide the necessary space and time to voice their positions (Siemsen et al., 2009). We would also encourage field office leaders to reach out to local aid workers personally, using informal settings to obtain accurate information about the country (Salem et al., 2017, 2019). Once the essential players are identified, the cluster should continue to organize ongoing trainings where cluster members can get acquainted with each other and the cluster.

\section{ACKNOWLEDGMENTS}

The authors thank the Department Editor, the Senior Editor, and the three reviewers for their insightful suggestions and comments that significantly improved the study. Furthermore, the authors express their gratitude to Gloria Urrea, Fabian Sting, and Dennis Gioia for their helpful feedback as well as the seminar participants at the Kuehne Logistics University, Rotterdam School of Management, London School of Economics, Bocconi University, Ludwig Maximilian University of Munich, and Technical University of Munich and the study participants for their valuable insights. In addition, the lead author appreciates and thanks the German Academic National Foundation for funding her PhD studies.

\section{O R C I D}

Lea Ruesch (10 https://orcid.org/0000-0002-7344-2403

Murat Tarakci (1) https://orcid.org/0000-0003-1936-6267

Maria Besiou (10 https://orcid.org/0000-0001-6401-2738

Niels Van Quaquebeke (DiD https://orcid.org/0000-0002-61414659

\section{RE F E R E N C E S}

Abidi, H., de Leeuw, S., \& Klumpp, M. (2015). The value of fourth-party logistics services in the humanitarian supply chain. Journal of Humanitarian Logistics and Supply Chain Management, 5(1), 35-60. https: //doi.org/10.1108/JHLSCM-02-2014-0010

Aguinis, H., \& Solarino, A. M. (2019). Transparency and replicability in qualitative research: The case of interviews with elite informants. Strategic Management Journal, 40, 1-25.

ALNAP \& UNEG. (2011). Haiti Earthquake response. Mapping and analysis of gaps and duplications in evaluations. https://www.alnap.org/help-library/haiti-earthquake-response-mappingand-analysis- of-gaps-and-duplications-in-evaluations

Altay, N., \& Labonte, M. (2014). Challenges in humanitarian information management and exchange: Evidence from Haiti. Disasters, 38(1), 1-23. PMID: 24325236
Altay, N., \& Pal, R. (2014). Information diffusion among agents: Implications for humanitarian operations. Production and Operations Management, 23(6), 1015-1027. https://doi.org/10.1111/poms.12102

Arslan, B., \& Tarakci, M. (2022). Negative spillovers across partnerships for responsible innovation: Evidence from the 2014 Ebola outbreak. J Management Studies, 59(1), 126-162. https://doi.org/10.1111/joms.12607

Balcik, B., Beamon, B. M., Krejci, C. C., Muramatsu, K. M., \& Ramirez, M. (2010). Coordination in humanitarian relief chains: Practices, challenges and opportunities. International Journal of Production Economics, 126(1), 22-34. https://doi.org/10.1016/j.ijpe.2009.09.008

Bealt, J., Fernández Barrera, J. C., \& Mansouri, S. A. (2016). Collaborative relationships between logistics service providers and humanitarian organizations during disaster relief operations. Journal of Humanitarian Logistics and Supply Chain Management, 6(2), 118-144. https:// doi.org/10.1108/JHLSCM-02-2015-0008

Berenguer, G., \& Shen, Z. - J. (2019). Challenges and strategies in managing nonprofit operations: An operations management perspective. Manufacturing \& Service Operations Management, 22, 1-18.

Besiou, M., \& Van Wassenhove, L. N. (2015). Addressing the challenge of modeling for decision-making in socially responsible operations. Production and Operations Management, 24(9), 1390-1401.

Besiou, M., \& Van Wassenhove, L. N. (2020). Humanitarian operations: A world of opportunity for relevant and impactful research. Manufacturing \& Service Operations Management, 22(1), 135-145.

Borshchev, A., \& Filippov, A. (2004). From system dynamics to agent based modeling. Simulation, 66(11), 25-29.

Brinkhoff, A., Özer, Ö., \& Sargut, G. (2015). All you need is trust? An examination of inter-organizational supply chain projects. Production and Operations Management, 24(2), 181-200. https://doi.org/10.1111/poms. 12234

Burton, R. M., \& Obel, B. (2011). Computational modeling for what-is, what-might-be, and what-should-be studies-And triangulation. Organization Science, 22(5), 1195-1202. https://doi.org/10.1287/orsc.1100. 0635

Campbell, L. (2016). How can we improve humanitarian coordination across a response? Briefing Paper. ALNAP, London, UK. http://rgdoi.net/10. 13140/RG.2.2.18224.46081

CBC. (2012, January 5). Special report. Haiti earthquake. CBC. https://www. cbc.ca/news/world/special-report-haiti-earthquake-1.1137266.

Cezanne, C., \& Saglietto, L. (2015). Redefining the boundaries of the firm: The role of 4PLs. The International Journal of Logistics Management, 26(1), 30-41. https://doi.org/10.1108/IJLM-06-2012-0054

Chandrasekaran, A., Linderman, K., \& Sting, F. J. (2018). Avoiding epistemological silos and empirical elephants in OM: How to combine empirical and simulation methods? Journal of Operations Management, 63(1), 1-5. https://doi.org/10.1016/j.jom.2018.11.003

Corbin, J., \& Strauss, A. (2014). Basics of qualitative research: Techniques and procedures for developing grounded theory. Sage Publications.

Delizonna, L. (2017, August 24). High-performing teams need psychological safety. Here's how to create it. Harvard Business Review. https://hbr.org/2017/08/high-performing-teams-need-psychologicalsafety-heres-how-to-create-it

Dolinskaya, I. S., Smilowitz, K. R., \& Ross, M., \& A. Foundation (2011). Decentralized approaches to logistics coordination in humanitarian relief. Proceedings of the 2011 Industrial Engineering Research Conference, Reno, Nevada.

Dubey, R., Altay, N., \& Blome, C. (2019). Swift trust and commitment: The missing links for humanitarian supply chain coordination? Annals of Operations Research, 283(1-2), 159-177. https://doi.org/10. 1007/s10479-017-2676-z

Dubey, R., Singh, T., \& Gupta, O. K. (2015). Impact of agility, adaptability and alignment on humanitarian logistics performance: Mediating effect of leadership. Global Business Review, 16(5), 812-831. https://doi.org/ 10.1177/0972150915591463

Eftekhar, M., Li, H., Van Wassenhove, L. N., \& Webster, S. (2017). The role of media exposure on coordination in the humanitarian setting. Production and Operations Management, 26(5), 802-816. https://doi.org/10. 1111/poms.12669 
Ergun, Ö., Gui, L., Heier Stamm, J. L., Keskinocak, P., \& Swann, J. (2014). Improving humanitarian operations through technology-enabled collaboration. Production and Operations Management, 23(6), 1002-1014. https://doi.org/10.1111/poms.12107

Faraj, S., \& Xiao, Y. (2006). Coordination in fast-response organizations. Management Science, 52(8), 1155-1169. https://doi.org/10.1287/mnsc. 1060.0526

Frennesson, L., Kembro, J., de Vries, H., Van Wassenhove, L., \& Jahre, M. (2020). Localisation of logistics preparedness in international humanitarian organisations. JHLSCM, 11(1), 81-106. https://doi.org/10.1108/ JHLSCM-06-2020-0048

Gehman, J., Glaser, V. L., Eisenhardt, K. M., Gioia, D., Langley, A., \& Corley, K. G. (2018). Finding theory-method fit: A comparison of three qualitative approaches to theory building. Journal of Management Inquiry, 27(3), 284-300. https://doi.org/10.1177/1056492617706029

Gioia, D. A. Personal Communications (E-Mail)/ Follow-up on Q\&A at AOM 2021: Unit of analysis in grounded theory and inter-organizational relationship research.

Gioia, D. A., Corley, K. G., \& Hamilton, A. L. (2013). Seeking qualitative rigor in inductive research: Notes on the Gioia methodology. Organizational Research Methods, 16(1), 15-31. https://doi.org/10.1177/ 1094428112452151

Glaser, B. G., \& Strauss, A. (1967). The discovery of grounded theory: Strategies for qualitative research. Aldine.

Gralla, E., Goentzel, J., \& Fine, C. (2014). Assessing trade-offs among multiple objectives for humanitarian aid delivery using expert preferences. Production and Operations Management, 23(6), 978-989. https:// doi.org/10.1111/poms.12110

Greer, L. L., Van Bunderen, L., \& Yu, S. (2017). The dysfunctions of power in teams: A review and emergent conflict perspective. Research in Organizational Behavior, 37, 103-124. https://doi.org/10.1016/j.riob. 2017.10.005

Grimm, V., Berger, U., DeAngelis, D. L., Polhill, J. G., Giske, J., \& Railsback, S. F. (2010). The ODD protocol: A review and first update. Ecological Modelling, 221(23), 2760-2768. https://doi.org/10.1016/j.ecolmodel. 2010.08.019

Gunasekaran, A., Dubey, R., Wamba, S. F., Papadopoulos, T., Hazen, B. T., \& Ngai, E. W. T.. (2018). Bridging humanitarian operations management and organisational theory. International Journal of Production Research, 56(21), 6735-6740. https://doi.org/10.1080/00207543.2018. 1551958

Hofe, A. R., Knemeyer, A. M., \& Dresner, M. E. (2009). Antecedents and dimensions of customer partnering behavior in logistics outsourcing relationships. Journal of Business Logistics, 30(2), 141-159. https:// doi.org/10.1002/j.2158-1592.2009.tb00116.x

Hoffmann, W., Lavie, D., Reuer, J. J., \& Shipilov, A. (2018). The interplay of competition and cooperation. Strategic Management Journal, 39(12), 3033-3052. https://doi.org/10.1002/smj.2965

Humanitarian Policy Group. (2015). According to need? Needs assessment and decision-making in the humanitarian sector. Report. Humanitarian Policy Group.

Inter-Agency Support Branch. (2020). Note on IASC coordination structures at country level. NGO Coordination. https: //ngocoordination.org/system/files/documents/resources/note-oncoordination-structures-2019-final_for-dissemination.pdf

Jahre, M., \& Jensen, L. (2010). Coordination in humanitarian logistics through clusters. International Journal of Physical Distribution \& Logistics Management, 40(8/9), 657-674.

Jensen, L. (2012). Humanitarian cluster leads: Lessons from 4PLs. Journal of Humanitarian Logistics and Supply Chain Management, 2(2), 148-160. https://doi.org/10.1108/20426741211260732

Kim, P. H., Dirks, K. T., \& Cooper, C. D. (2009). The repair of trust: A dynamic bilateral perspective and multilevel conceptualization. Academy of Management Review, 34(3), 401-422. https://doi.org/10.5465/amr. 2009.40631887

Knox-Clarke, P., \& Campbell, L. (2015). Exploring coordination in humanitarian clusters. ALNAP, London, UK. http://www.alnap.org/resource/ 20360
Kramer, R. M., \& Lewicki, R. J. (2010). Repairing and enhancing trust: Approaches to reducing organizational trust deficits. Academy of Management Annals, 4(1), 245-277. https://doi.org/10.5465/19416520.2010. 487403

Lewicki, R. J., \& Brinsfield, C. (2017). Trust repair. Annual Review of Organizational Psychology and Organizational Behavior, 4(1), 287-313. https://doi.org/10.1146/annurev-orgpsych-032516-113147

Lewin, R., Besiou, M., Lamarche, J.-B., Cahill, S., \& Guerrero-Garcia, S. (2018). Delivering in a moving world...looking to our supply chains to meet the increasing scale, cost and complexity of humanitarian needs. Journal of Humanitarian Logistics and Supply Chain Management, 8(4), 518-532. https://doi.org/10.1108/JHLSCM-10-2017-0048

Lincoln, Y., \& Guba, E. (1985). Naturalistic inquiry. Sage.

LogCluster. (2019). Background. https://logcluster.org/about-us

Lu, Q., Goh, M., \& De Souza, R. (2018). An empirical investigation of swift trust in humanitarian logistics operations. Journal of Humanitarian Logistics and Supply Chain Management, 8(1), 70-86. https://doi.org/10.1108/ JHLSCM-07-2017-0033

Mayer, R. C., \& Davis, J. H. (1995). An integrative model of organizational trust. Academy of Management Review, 20(3), 709-734. https://doi.org/ $10.2307 / 258792$

McLaren, M., \& Loosemore, M. (2019). Swift trust formation in multinational disaster project management teams. International Journal of Project Management, 37(8), 979-988. https://doi.org/10.1016/j.ijproman. 2019.09.003

Meyerson, D., Weick, K. E., \& Kramer, R. M. (1996). Swift trust and temporary groups. Sage.

Miles, M. B., \& Huberman, A. M. (1994). Qualitative data analysis (2nd ed.). Sage.

Minson, J. A., Mueller, J. S., \& Larrick, R. P. (2018). The contingent wisdom of dyads: When discussion enhances vs. undermines the accuracy of collaborative judgments. Management Science, 64(9), 4177-4192. https://doi.org/10.1287/mnsc.2017.2823

Mortensen, M., \& Neeley, T. B. (2012). Reflected knowledge and trust in global collaboration. Management Science, 58(12), 2207-2224. https:// doi.org/10.1287/mnsc. 1120.1546

Moshtari, M. (2016). Inter-organizational fit, relationship management capability, and collaborative performance within a humanitarian setting. Production and Operations Management, 25(9), 1542-1557. https://doi.org/ 10.1111/poms. 12568

Moshtari, M., \& Gonçalves, P. (2011). Understanding the drivers and barriers of coordination among humanitarian organizations. POMS 23rd Annual Conference, Chicago, IL, April 20-23.

Nag, R., \& Gioia, D. A. (2012). From common to uncommon knowledge: Foundations of firm-specific use of knowledge as a resource. Academy of Management Journal, 55(2), 421-457. https://doi.org/10.5465/amj.2008. 0352

Özer, Ö., Subramanian, U., \& Wang, Y. (2018). Information sharing, advice provision, or delegation: What leads to higher trust and trustworthiness? Management Science, 64(1), 474-493. https://doi.org/10.1287/ mnsc. 2016.2617

Özer, Ö., \& Zheng, Y. (2017). Trust and trustworthiness. In K. Donohue, E. Katok, \& S. Leider (Eds.), The handbook of behavioral operations (pp. 489-519). John Wiley \& Sons.

Pettit, S., \& Beresford, A. (2009). Critical success factors in the context of humanitarian aid supply chains. International Journal of Physical Distribution \& Logistics Management, 39(6), 450-468.

Salem, M., Van Quaquebeke, N., \& Besiou, M. (2017). How field office leaders drive learning and creativity in humanitarian aid: Exploring the role of boundary-spanning leadership for expatriate and local aid worker collaboration. Journal of Organizational Behavior, 39(5), 1-18.

Salem, M., Van Quaquebeke, N., Besiou, M., \& Meyer, L. (2019). Intergroup leadership: How leaders can enhance performance of humanitarian operations. Production and Operations Management, 28(11), 2877-2897. https://doi.org/10.1111/poms.13085

Sankaranarayanan, K., Castañeda, J. A., \& Villa, S. (2018). Future research in humanitarian operations: A behavioral operations perspective. In G. Kovács, K. Spens, \& M. Moshtari (Eds.), The Palgrave handbook of 
humanitarian logistics and supply chain management (pp. 71-117). Palgrave Macmillan.

Schiffling, S., Hannibal, C., Fan, Y., \& Tickle, M. (2020). Coopetition in temporary contexts: Examining swift trust and swift distrust in humanitarian operations. International Journal of Operations \& Production Management, 40(9), 1449-1473.

Secretary-General of the United Nations Ban Ki-moon. (2016). One humanity: shared responsibility. United Nations. General Assembly. https://cerf. un.org/sites/default/files/resources/A_70_709_E.pdf

Siemsen, E., Roth, A. V., Balasubramanian, S., \& Anand, G. (2009). The influence of psychological safety and confidence in knowledge on employee knowledge sharing. Manufacturing \& Service Operations Management, 11(3), 429-447.

Stadtler, L., \& Van Wassenhove, L. N. (2016). Coopetition as a paradox: Integrative approaches in a multi-company, cross-sector partnership. Organization Studies, 37(5), 655-685. https://doi.org/10.1177/ 0170840615622066

Sting, F., Stevens, M., \& Tarakci, M. (2019). Temporary deembedding buyer-supplier relationships: A complexity perspective. Journal of Operations Management, 65(2), 114-135. https://doi.org/10.1002/joom.1008

Tatham, P., \& Kovács, G. (2010). The application of "swift trust" to humanitarian logistics. International Journal of Production Economics, 126(1), 35-45. https://doi.org/10.1016/j.ijpe.2009.10.006

Tomasini, R., \& Van Wassenhove, L. (2009). Humanitarian logistics. Springer.

Toyasaki, F., Arikan, E., Silbermayr, L., \& Falagara Sigala, I. (2017). Disaster relief inventory management: Horizontal cooperation between humanitarian organizations. Production and Operations Management, 26(6), 1221-1237. https://doi.org/10.1111/poms.12661

United Nations. (2016). The 17 goals. Department of Economic and Social Affairs. https://sdgs.un.org/goals

Urrea, G., Pedraza-Martinez, A. J., \& Besiou, M. (2019). Volunteer management in charity storehouses: Experience, congestion and operational performance. Production and Operations Management, 28(10), 2653-2671. https://doi.org/10.1111/poms.13073

van Bunderen, L., Greer, L. L., \& van Knippenberg, D. (2018). When interteam conflict spirals into intrateam power struggles: The pivotal role of team power structures. Academy of Management Journal, 61(3), 11001130. https://doi.org/10.5465/amj.2016.0182

Vangen, S., \& Huxham, C. (2003a). Enacting leadership for collaborative advantage: Dilemmas of ideology and pragmatism in the activities of partnership managers. British Journal of Management, 14(s1), S61-S76. https://doi.org/10.1111/j.1467-8551.2003.00393.x

Vangen, S., \& Huxham, C. (2003b). Nurturing collaborative relations: Building trust in interorganizational collaboration. The Journal of Applied Behavioral Science, 39(1), 5-31. https://doi.org/10.1177/ 0021886303039001001

Villena, V. H., \& Gioia, D. A. (2018). On the riskiness of lower-tier suppliers. Managing sustainability in supply networks. Journal of Operations Management, 64(1), 65-87. https://doi.org/10.1016/j.jom.2018.09.004

Wang, Q., Huo, B., \& Zhao, X. (2020). What makes logistics integration more effective? Governance from contractual and relational perspectives. Journal of Business Logistics, 41(3), 259-281. https://doi.org/10.1111/ jbl. 12236

Win, A. (2008). The value a 4PL provider can contribute to an organisation. International Journal of Physical Distribution \& Logistics Management, 38(9), 674-684.

\section{SUPPORTING INFORMATION}

Additional supporting information may be found in the online version of the article at the publisher's website.

How to cite this article: Ruesch, L., Tarakci, M., Besiou, M., \& Van Quaquebeke, N. (2022). Orchestrating coordination among humanitarian organizations. Production and Operations Management, 1-20. https://doi.org/10.1111/poms.13660 